\title{
Novedades Legislativas
}

Eduardo Baldi ${ }^{1}$ Universidad Nacional de La Plata

Revista Derechos en Acción ISSN 2525-1678/ e-ISSN 2525-1686

Año 4/No 11 Otoño 2019 (21 marzo a 21 junio), 402-408

DOl: https://doi.org/10.24215/25251678e282

ORCID: https://orcid.org/0000-0003-3933-2611

\section{Nación}

Ley $\mathbf{N}^{\circ}$ 27.501. Reforma a la Ley $\mathbf{N}^{\circ} \mathbf{2 6 . 4 8 5}$ de Protección Integral a las Mujeres. Sanción del acoso callejero

La iniciativa tipifica al acoso callejero como delito en el Código Penal y modifica la Ley de Protección Integral para prevenir, sancionar y erradicar la violencia contra las mujeres №26.485.

La norma establece penas contra las ofensas a las mujeres que tengan lugar "en espacios públicos o de acceso público, transportes y centros comerciales". Asimismo, define este tipo de violencia como "aquella ejercida contra las mujeres por una o más personas a través de conductas o expresiones verbales o no verbales, con connotación sexual, que afecten o dañen su dignidad, integridad, libertad, libre circulación o permanencia, o generen un ambiente hostil u ofensivo".

También, prevé una línea telefónica para dar asesoramiento ante estos casos e "insta a las fuerzas de seguridad a actuar en protección de las mujeres en espacios públicos cuando se vieran afectadas por este tipo de delitos".

\footnotetext{
1 Abogado (UNLP), docente de la Facultad de Ciencias Jurídicas y Sociales de la Universidad Nacional de La Plata. E-mail: eduardoabaldi@hotmail.com
} 
Decreto No 233/2019. Creación del Comando General Electoral para custodiar las Elecciones Nacionales

A través de la norma, se le asignan las funciones de coordinación y ejecución referentes a las medidas de seguridad que establece el Código Electoral Nacional. Se establece que esta fuerza trabajará en "la vigilancia de los locales donde funcionen las mesas receptoras de votos, de las sedes e infraestructuras destinadas al ingreso y procesamiento de datos para el recuento provisional de resultados (...), de las sedes de los Juzgados Federales con Competencia Electoral y Juntas Electorales Nacionales de cada distrito, la custodia de las urnas así como la documentación durante su transporte y hasta la finalización del escrutinio definitivo en cada distrito".

Por otra parte, la norma prevé que el Ministerio de Defensa destinará los efectivos del Ejército, la Armada y la Fuerza Aérea que sean necesarios. Asimismo, el Ministerio de Seguridad hará lo mismo con agentes de la Gendarmería, Prefectura, Policía de Seguridad Aeroportuaria y Policía Federal. Los gobiernos provinciales y de la ciudad de Buenos Aires también destinarán efectivos de sus respectivas fuerzas.

Decreto $\mathbf{N}^{\circ}$ 258/2019. Creación de un plan anticorrupción 2019-2023

Se basa en artículos de la Constitución Nacional y en varias convenciones ratificadas por el país. Estará a cargo de la Oficina Anticorrupción que deberá crear un consejo asesor de carácter ad honorem para el seguimiento del plan. Mediante un extenso anexo, en el que se detallan diversas políticas desarrolladas por el Gobierno en estos últimos tres años y lineamientos a futuro para lograr objetivos de lucha contra corrupción" para "consolidar y profundizar el camino de la transparencia, la integridad, el fortalecimiento institucional y la rendición de cuentas" en la administración pública. 


\section{Decreto $\mathbf{N}^{\circ}$ 259/2019. Reglamenta Código Electoral. Elimina listas "colectoras"}

La norma prohíbe que en las elecciones primarias, abiertas, simultáneas y obligatorias, y en las elecciones generales, se inincluya en las distintas secciones de la boleta a agrupaciones que tengan diferente denominación.

Dicha regla se exceptúa para el caso en que no participen agrupaciones de igual denominación en todas las categorías de cargos a elegir, en las que se podrá adherir la boleta a listas de una única agrupación política de orden nacional de diferente denominación.

\section{Decreto de Necesidad y Urgencia $\mathbf{N}^{\circ}$ 274/2019. Sustitución de la Ley de Lealtad Comercial ( $\left.\mathbf{N}^{\circ} 22802\right)$}

El citado Decreto de Necesidad y Urgencia (DNU) aprueba una nueva Ley de Lealtad Comercial. El objetivo de la norma es "asegurar la lealtad y transparencia en las relaciones comerciales y garantizar el acceso a información esencial sobre los productos y servicios comercializados" y establece sanciones ante su incumplimiento.

El texto prevé que: "Están probibidos los actos de competencia desleal, cualquiera sea la forma que adopten, el medio a través del cual se realicen y el mercado en el que tengan lugar. No será necesario acreditar la generación de un daño, pudiendo éste ser actual o potencial".

Asimismo, define a los mismos como "toda acción u omisión que, por medios indebidos, resulte objetivamente apta para afectar la posición competitiva de una persona o el adecuado funcionamiento del proceso competitivo" y describe 13 conductas que se consideran contrarias a la lealtad.

La autoridad de aplicación será la Secretaría de Comercio Interior del Ministerio de Producción y Trabajo. Ante una violación a lo previsto por la ley podrá establecer la clausura del establecimiento comercial por hasta 30 días o multas por un monto equivalente a 1 y 10.000.000 de Unidades Móviles (UM), 
valor que será actualizado automáticamente cada año en virtud de la variación del Índice de Precios al Consumidor (IPC) que publica el Indec. Las multas pueden llegar hasta los \$200 millones.

Decreto $N^{\circ} 343 / 2019$. Convocatoria a elecciones nacionales y ratificación de las fechas del calendario electoral que habían sido informadas

Las elecciones primarias, abiertas, simultáneas y obligatorias (PASO) serán el 11 de agosto, mientras que el 27 de octubre serán los comicios generales para elegir a presidente, vicepresidente, diputados y senadores. En caso de un eventual balotaje este tendrá lugar el 24 noviembre.

"El Ministerio del Interior, Obras Públicas y Vivienda, a través de la Dirección Nacional Electoral, adoptará las medidas necesarias para la organización y realización de los comicios objeto de la presente convocatoria", expresa el decreto.

Además, incluye un anexo que clarifica cuáles son los cargos legislativos nacionales que se elegirán este año en cada distrito.

Resolución $N^{\circ}$ 234/19. Ministerio de Seguridad. dispone la creación de la Unidad de Garantía de los Derechos Humanos de las Fuerzas Policiales y de Seguridad bajo la órbita de la Dirección de Violencia Institucional

La misma tiene por objetivos, entre otros, relevar información y producir estudios de diagnóstico que permitan identificar las fortalezas y debilidades de la normativa relativa a la protección de los derechos humanos de los efectivos de las Fuerzas Policiales y de Seguridad Federales y contribuir a fortalecer la cultura del respeto y el ejercicio de los Derechos Humanos a través de la formación, promoción y difusión de los derechos humanos en las distintas etapas de formación y capacitación de los efectivos de las Fuerzas Policiales y de Seguridad Federales. 
Resolución Conjunta No $4458 / 19$ del Ministro de Producción y Trabajo y del Administrador Federal de Ingresos Públicos (AFIP). Actualiza el Régimen de Exportación Simplificada denominado "EXPORTA SIMPLE"

El mencionado régimen tiene por objeto facilitar las operaciones de exportación de menor cuantía con fines comerciales.

Resolución No 395/19 del Ministerio de Seguridad. Habilita el uso de armas electrónicas (Taser)

El Ministerio de Seguridad de la Nación habilitó la utilización de pistolas Taser, al aprobar el Reglamento General para el empleo de armas electrónicas no letales por parte de los miembros de las Fuerzas de Policiales y de Seguridad Federales. Las mismas son conocidas popularmente bajo el nombre de Taser.

\section{Provincia de Buenos Aires}

Ley $\mathbf{N}^{\circ}$ 15.134. Ley Micaela bonaerense que establece capacitación obligatoria en género para los tres poderes del Estado

Replica a la Ley Nacional $N^{\circ} 27499$, sancionada a fines de 2018, y tiene como objetivo de sensibilizar a quienes integran los diferentes estamentos del Estado Provincial para prevenir, sancionar y erradicar la violencia contra la mujer

Decreto $\mathrm{N}^{\mathrm{o}}$ 266/2019. Reglamenta la ley $\mathrm{N}^{\circ} 14848$ de paridad de género para la conformación de las listas electorales

La norma dispone que la conformación de listas deberá estar integrada por candidatas y candidatos de manera intercalada, en forma alterna y secuencial, en la totalidad de la lista, de modo tal que no haya dos personas continuas del mismo género en una misma lista.

Asimismo, prevé que si al conformar la lista definitiva, según el resultado de la elección primaria, no se cumpliere con los requisitos de conformación paritaria, la Junta Electoral de la Provincia de Buenos Aires intimará a la agrupación política a 
que la reordene en el término de 48 horas contado a partir de la notificación de dicha intimación.

Decreto $\mathrm{N}^{\mathrm{o}}$ 268/2019. Fija las fechas de las elecciones de autoridades bonaerenses

Se convoca a elecciones primarias, abiertas, simultáneas y obligatorias para el 11 de agosto, mientras que las generales serán el 27 de octubre. Las fechas coinciden con las dispuestas para la elección de cargos a nivel nacional.

Decreto $N^{\circ}$ 270/19. Nueva prórroga de la emergencia en materia de infraestructura, hábitat, vivienda y servicios públicos

Mediante el dictado de esta norma, se prorroga por el período de un año y por única vez, la emergencia en materia de infraestructura, hábitat, vivienda y servicios públicos, que fuera establecida mediante la Ley $\mathrm{N}^{\circ} 15.022$ en el año 2018, y previamente declarada mediante la Ley $\mathrm{N}^{\mathrm{o}} 14.812$ y prorrogada por el Decreto $\mathrm{N}^{\circ} 52 / 17$.

La emergencia en diversas materias en la provincia de Buenos Aires, es un tema que nos acompaña durante los últimos años.

\section{Resoluciones $\mathbf{N}^{\circ} 618$ y $619 / 2019$ del Ministro de Infraes-} tructura y Servicios Públicos. Aumento de peajes

Las mencionadas resoluciones aprueban los nuevos cuadros tarifarios, que incluye aumentos de alrededor del 33\% en los peajes de la Autopista Buenos Aires - La Plata y de las rutas del Sistema Vial Integrado del Atlántico, que comunican gran parte de la costa bonaerense.

Los aumentos se establecen luego de haberse realizado las correspondientes audiencias públicas los días 19 y 20 de marzo en la ciudad de La Plata, capital de la provincia, y establecen un valor de $\$ 100$ ( $\$ 120$ para fines de semana y temporada de verano) para los peajes de Samborombón y Maipú, en la Ruta 2 ; y, un valor de $\$ 66$ (\$84 en hora pico) en la estación de peaje 
Hudson, en la Autopista Buenos Aires La Plata, sentido a Capital Federal.

Resolución Conjunta $\mathbf{n}^{\circ} \mathbf{1} / \mathbf{1 9}$ de los Ministros de Desarrollo Social y de Infraestructura y Servicios Públicos de la Provincia. Establece una bonificación en la tarifa eléctrica para clubes de barrios y pueblos

Mediante el dictado de esta norma, se establece una bonificación del 30\% de los conceptos eléctricos facturados a los Clubes de Barrio y de Pueblo radicados en la provincia y encuadrados en las categorías tarifarias Pequeñas y Medianas Demanda y Pequeñas Demandas Rurales, a partir del $1^{\circ} \mathrm{de}$ mayo de este año o desde el primer día del mes en el que acrediten el cumplimiento de los requisitos.

Esta sección se realiza gracias al invalorable aporte de Palabras del Derecho:

www.palabrasdelderecho.com.ar

Instagram: palabrasdelderecho

www.facebook.com/palabrasdelderecho/

Twitter: @palabrasdelderecho 